\title{
LA FRONTERA COLOMBO-PANAMEÑA: UNA FRONTERA SELVÁTICA, CERRADA AL PROGRESO, PERO ABIERTA A LAS MIGRACIONES MÁS DISÍMILES ${ }^{*}$
}

\author{
Por \\ Acela Pujol G.**
}

\begin{abstract}
RESUMEN
Este artículo se enfoca al estudio de la geografía y las poblaciones indígenas y latinas que habitan la frontera este de Panamá, misma que marca el límite político de América Central y Sudamérica. La región fronteriza Panamá-Colombia es una región marginada y olvidada por el desarrollo; por largo tiempo ha sido refugio de las poblaciones que huyen de los conflictos políticos centroamericanos. Esta zona además de su aislamiento físico, representa una frontera social, un área separada de la economía nacional.
\end{abstract}

\begin{abstract}
This article focuses on the geography and the indigenous and Latin populations that inhabit the eastern frontier region of Panama. This region marks the political boundary between South and Central America. The Panama-Columbia frontier region is an area overlooked and forgotten, it has long been the refuge of populations fleeing from Central American political conflicts. In addition to its physical isolation, this zone represents a social frontier, an area separate from the national economy.
\end{abstract}

La región que ocupa la frontera este panameña que marca el límite político de América Central y que la separa del país sudamericano de Colombia, es una zona marginada, con territorios todavía no incorporados bajo la forma de tierras baldías, reservas indígenas y comarcas.

* Este artículo se presentó en el evento "Fronteras en perspectiva internacional", efectuado en la Universidad Autónoma de Baja California los días 17 y 18 de noviembre de 1997.

** Departamento de Geografía, Universidad de Panamá. 
Por siglos, ha sido refugio de poblaciones desplazadas, perseguidas o excluidas del sistema político y económico vigente, y más que frontera política, ha funcionado como una frontera social, como un área de separación y aislamiento de la economía nacional.

\section{EL MEDIO FÍSICO}

La geografía de la región es muy variada y compleja, afectada por procesos geomorfológicos típicos de selva densa que guardan un equilibrio muy precario con las acciones antrópicas desorganizadas. Su clima es tropical húmedo con temperaturas medias anuales entre $25^{\circ} \mathrm{C}$ y $27^{\circ} \mathrm{C}$, y precipitaciones ente 2000 y $3000 \mathrm{~mm}$ de caída al año, con distribución geográfica desigual, ya que llueve más en las tierras altas y, por efectos de la deforestación, la estación seca se acentúa cada vez más en las tierras bajas.

Este clima mantiene un bosque húmedo con una alta biodiversidad que incluye árboles maderables y variedad de palmeras en los lugares mal drenados. En relación con la topografía, existen varios pisos de vegetación (arbóreo, arbustivo y herbáceo), y en parajes, lianas y enredaderas. Por la acción del hombre, se observan formas de transición entre el bosque tropical húmedo y el tropical seco.

Los suelos son arcillosos, rojos, profundos y en procesos de lateritización. Existen también suelos grisáceos e hidromórficos en los lugares mal drenados, y suelos aluviales en los cursos medios y bajos de los ríos.

En 1980, el gobierno nacional creó el Parque Nacional Darién, el más grande de Centroamérica, y que fue declarado reserva de la biosfera por la Unesco en junio de 1983. Este parque, con una extensión de 575000 ha, comprende las cuencas hidrográficas de los ríos Tuira, Balsas, Sambú y Jaqué, así como parte del río Chucunaque, y dentro de estas cuencas habitan los grupos indígenas emberás-wounaan y kunas. Para estos grupos, la creación del parque nacional guarda especial importancia, pues incluye áreas y poblados vitales para su cultura, como el poblado de Boca de Trampa, en el nacimiento del río Sambú, primer pueblo emberá de Panamá, y el poblado de Paya, en el río Paya, afluente del Tuira, que es el centro religioso y lugar sagrado de los kunas.

\section{LOS GRUPOS ÉTNICOS}

Hasta hace pocos años, la escasa ocupación humana se aglutinaba en dos núcleos diferentes: las comunidades indígenas de las comarcas emberáwounaan y kunas, y la población no indígena, compuesta por afromestizos, colombianos indocumentados, así como inmigrantes de otras partes del 


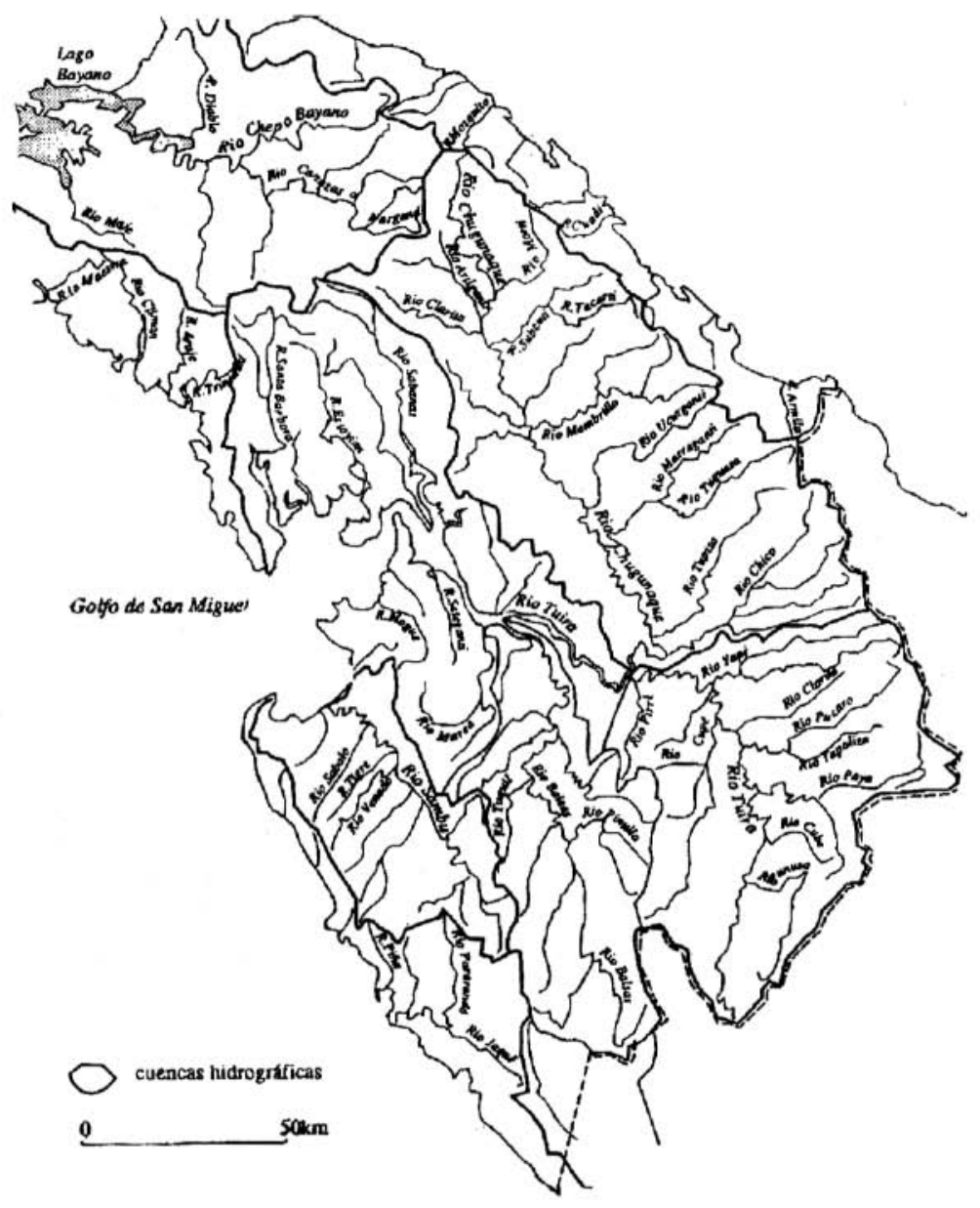

Figura 1. Red hidrográfica. 
país que llegaron a esta región en busca de tierras y medios de producción para mejorar sus condiciones de vida.

A partir de 1990, a estos grupos se suman los guerrilleros, bandoleros y paramilitares colombianos que, con sus pillajes y saqueos, mantienen alarmada a la población.

\section{La población indígena}

\section{El grupo Chocó}

El mayor número de ellos se encuentra en las orillas de los ríos Sambú, Jaque, Chico, Tuquesa y Tupisa (afluentes del Chucunaque), Tuira, Yape y Tucutí. Esta amplia extensión territorial contrasta con lo reducido de su población. Habitan en unas 84 comunidades de cinco o más viviendas (Censo 1990), muchas de las cuales se encuentran dentro de los distritos comarcales de Cémaco y Sambú ( 35 en total).

Las otras se localizan dispersas por la provincia, pero siempre a orillas de los ríos.

El censo de 1990 arrojó una población de 15168 indígenas, y su tasa de reproducción es una de las más altas del país (4.8).

El hecho de que el grupo mayoritario Chocó se encuentre en Colombia, donde su población puede estimarse aproximadamente en 500000 habitantes, y la continuidad del territorio común que habitan (provincia del Darién, departamento del Chocó), motiva a una facilidad evidente de migración, cuya orientación es de Colombia hacia Panamá, siendo el caso contrario una excepción.

Algunos asentamientos indígenas más recientes en la provincia del Darién (establecidos en la década de 1960), tienen su origen poblacional en los indios chocoes de lengua wounaan, de la región del río San Juan, en el sur de Colombia.

El hábitat de pluviselva, al cual su cultura denota una adaptación altamente especializada, es el medio ecológico típico, tradicional e ideal que orienta sus movimientos migratorios hacia las zonas geográficas donde impera este tipo de nicho ecológico.

A pesar de tener dos dialectos distintos (emberaá y wounaan, este último también llamado nonamá), el grupo Chocó ha sido tradicionalmente considerado como una sola cultura.

La agricultura es la actividad económica que los provee de su sustento básico. La cacería, la pesca, la cría de animales de corral y la recolección vegetal, constituyen faenas secundarias. Entre los chocoes se practican tres tipos de agricultura: la agricultura de plantación, cuyo exponente es el 
plátano y el guineo; la agricultura de roza, propia del cultivo del arroz y del maíz, y también utilizada para el cultivo de rizomas y raíces comestibles; y la agricultura de huerto, estereotipada por el pequeño huerto que rodea la típica vivienda chocó, y en el cual se concentran cultivos mixtos para la dieta diaria.

El cultivo del plátano se realiza en gran escala, con fines comerciales, a diferencia del guineo, que se siembra para el cultivo familiar. El cultivo del ñame presenta una desviación comercial, mientras que el del arroz ha manifestado un incremento apreciable por la demanda que presenta en el mercado y que garantiza la venta de la cosecha.

La variada fauna de la región selvática habitada por los chocoes, ofrece abundante provisión de proteína animal. Es muy frecuente, en la actualidad, el uso de armas de fuego, rifles o escopetas, aunque todavía es practicada, eventualmente, la cacería con lanzas e incluso machetes. Las trampas no han sido definitivamente desterradas del campo de sus técnicas, y el arco y la flecha están en franca retirada.

La pesca, labor básicamente masculina, se realiza mediante diversas técnicas: arpones o lanzas arponadas, con las cuales atraviesan los peces desde las piraguas a la orilla de los ríos. Las redes verticales son de uso especializado a la entrada de los esteros, y la participación de mujeres y niños en la pesca se da mediante la utilización de canastos fabricados con fibras vegetales.

El patrón tradicional de poblamiento es el de viviendas familiares separadas unas de otras a considerables distancias y esparcidas a lo largo de los ríos. Las aldeas propiamente dichas, son un fenómeno moderno, estimulado por la acción proselitista de misioneros, o bien, por programas de cambio dirigidos bajo la responsabilidad de agencias del gobierno nacional, que auspician las aldeas nucleadas para poder hacer llegar más fácilmente servicios estatales de educación, salud y atención agrícola.

La vivienda chocó típica, está construida sobre pilotes, que la levantan del suelo a una altura aproximada de tres metros. El techo tradicional es cónico, aunque en los últimos años se hacen frecuentes los techos a dos y cuatro aguas. Es una vivienda muy bien adaptada a la selva tropical.

La familia nuclear chocó se compone del matrimonio monogámico y de sus hijos. Los chocoes del Darién reconocen su relación —e incluso su origen-con los colombianos, y los matrimonios son comunes. Tampoco la variante lingüística emberá y wounaan parece constituir un impedimento para las uniones matrimoniales.

Entre los indios chocoes de Panamá y Colombia aparece la figura del chamán y presenta las caracterísitcas generales que son comunes a este importante personaje del mundo social - religioso de diversas culturas 
americanas - y, aunque no llega a adquirir hegemonía política, se convierte, no obstante, en personaje consultor en una comunidad que pudiera carecer de organización política y de todo tipo de jefatura o cacicazgo. Recibe el nombre de jaibana, y es la persona que puede entrar en comunicación con los distintos espíritus (jais) — numerosos y variados-, que pueblan el mundo espiritual chocó y logran de ellos consejos y ayuda para curar enfermedades.

El Congreso Regional Indígena del Darién, celebrado en 1969, estableció para el grupo Chocó, el patrón político Kuna, el cual se fue adaptando a los cambios sociales que consecuentemente iban ocurriendo en razón de la nuclearización habitacional y al sistema de representación y estructuración política emanada de la Constitución de 1972. Mediante la Ley 22 del 8 de noviembre de 1983, se definió la comarca Emberá, la cual está actualmente segmentada en dos distritos comarcales: Cémaco y Sambú.

\section{El grupo Kuna}

La población kuna ocupa dos tipos de hábitats distintos: el grupo mayoritario vive en la zona insular costera del Atlántico, conocida como archipiélago de las Mulatas o San Blas. El grupo minoritario ocupa las márgenes del ato río Chucunaque y del río Bayano. También, en número muy reducido (menos de 500), ciertos sectores del río Tuira. La zona es típica selva tropical húmeda, y el emplazamiento de los poblados (Púcuro y Paya) es a la orilla de los ríos.

Si bien se trata de la misma cultura, el grupo Kuna de San Blas, en razón de que ha estado en mayor contacto con los grupos no indios y su vinculación política y comercial ha sido estrecha, presenta aspectos aculturativos mucho más acentuados que el grupo continental, (este último, voluntariamente aislado y marginado por la falta de comunicaciones viales, ha mantenido los patrones culturales más puros).

Los dos grupos, a pesar de seguir los mismos patrones de organización política, no tienen una jefatura común para ambos. Se trata de sistemas gemelos pero independientes. Las relaciones entre ellos son, sin embargo, cordiales y están vinculados estrechamente por intereses comerciales. Los de San Blas, que participan cada vez más dentro de una economía de dinero, abandonan tecnologías tradicionales, incluso algunas de subsistencia tales como la cacería, y otras como la talla de objetos domésticos en madera, cultivo selectivo del tabaco, etcétera. Los kunas continentales son entonces, quienes los surten, en parte, de estos elementos, y a su vez, obtienen en los pueblos de las islas, productos tales como sal, telas y, 
eventualmente, algunos alimentos enlatados, procedentes de Panamá, Colombia o cualquier otro país que exporte al istmo.

La agricultura de subsistencia es realmente la base económica del grupo indígena kuna de tierra firme. No existen las plantaciones comerciales de coco, como entre los kunas de San Blas, o de plátano, como entre los indios chocoes. El poco excedente agrícola que se logra en especies tales como el café y raíces comestibles, por razones de extrema marginación geográfica, los indios kunas del alto Chucunaque y del Tuira, no pueden llevarlo ni a San Blas ni a Yaviza — con la sola excepción del tabaco y las semillas de cacao.

En la región continental se puede observar que la pesca fluvial es llevada a cabo tanto por los hombres como por las mujeres. Los hombres practican generalmente la pesca de arpones. Las mujeres y los niños coadyuvan en las labores de la pesca ocupándose de la recolección de camarones y moluscos.

Tanto los kunas de la región de San Blas, como los de la región continental, siguen el mismo patrón de poblamiento: aldeas nucleadas que en la región continental se encuentran a orilla de los ríos.

El matrimonio kuna es de tipo monogámico. La residencia es matrilocal, lo que, por relación económica, se traduce en una destaca posición social de la mujer. De acuerdo con esto el esposo entra a formar parte de la economía familiar. Realmente, su función es activa e importante, puesto que la fuerza de un hombre joven será necesaria para las duras faenas de la agricultura, la cacería y la pesca.

La medicina es tal vez el elemento de la cultura kuna donde se muestra la mayor especialización y una más estrecha relación tanto con el mundo vegetal y animal, como con el mundo sobrenatural. Para enfrentarse al momento crítico de una enfermedad, esta cultura cuenta con tres personajes, cada uno de ellos especializados en un aspecto de la prevención, curación y erradicación de las enfermedades y epidemias. Uno de ellos es el innatuledi, que se mueve en el mundo de la botánica, excluyendo la comunicación efectiva con el mundo de los espíritus. Sus prácticas terapéuticas incluyen pócimas, baños curativos, emplastos, fricciones, sahumerios, baños de vapor y cirugía menor.

El nele, o su versión femenina nelegua, es la figura de tipo shamanístico. Es el médico que tiene acceso al mundo de los espíritus de manera efectiva y continua. El nele es un ser predestinado, cuya condición se conoce al momento de su nacimiento.

El tercer tipo de especialista es el que ha sido llamado absoguedi o summaket tule. Se especializa en cantos que pueden espantar los espíritus causantes de las epidemias. 
La medicina kuna, con sus amplios conocimientos de botánica curativa y sus elaborados ritos de carácter mágico, requiere largos años de estudios, y para ello se desplazan por todo el archipiélago y a Colombia.

La organización política kuna, presenta una jerarquización de jefatura de gran efectividad, y en cuanto al aspecto del mecanismo del gobierno tribal, se acerca al concepto más utópico que puede elaborarse sobre democracia. En cada isla o pueblo kuna existe un jefe o sahila, quien a su vez está supeditado a la autoridad de los tres sahilas tumadi o sahilas grandes o generales. Pero la autoridad de estos últimos, a su vez, aparece limitada y supeditada a las decisiones del Congreso General Kuna, que es realmente la máxima autoridad política dentro de esta cultura.

Las poblaciones kunas basan su estructuración política en el hecho de que el gobierno de Panamá les ha adjudicado reservas y les permite tener gobierno propio desde finales de la década de los veinte.

En el extremo oriental de la provincia de Darién, cercano a la línea limítrofe, los pueblos de Pucro y Paya constituyen el remanente kuna de esa área. No poseen reservas de tierras delimitadas según la ley, y en su organización política presentan todas las evidencias de un extremo rompimiento de los patrones políticos tradicionales. Este fenómeno no es de extrañar, puesto que los poblados constituyen un paso obligado de los grupos que constantemente emigran de Colombia hacia Panamá, y además, como sitio fronterizo, reciben continuamente el paso de visitantes y de funcionarios encargados del control y policía del área, lo cual los ha sometido a procesos aculturativos intensos. Esto puede observarse en un biligüismo generalizado, uniones matrimoniales exógenas e inexistencia del sistema político tradicional. No obstante, se conservan aún los patrones de asentamiento y vivienda, y las artesanías de tejido y la cesterías, son esmeradamente cultivadas.

\section{LOS LATINOS}

Tal como hemos señalado, la población que habita en la zona fronteriza es casi toda indígena. Los residentes criollos o latinos, integrados por los darienitas y algunos campesinos panameños sin tierras que emigran desde las provincias centrales en busca de tierras para cultivar, se quedan en las poblaciones de los cursos bajos y medios de los ríos, tales como Boca de Cupe, Yape, Pinogana, El Real y Yaviza, entre otros.

Practican la agricultura de subsistencia, el comercio de tiendas, la explotación forestal y, en menor escala, la ganadería extensiva. Estas actividades ganan cada día más adeptos en detrimento de la vegetación de selva densa. 
ACELA PUJOL G.

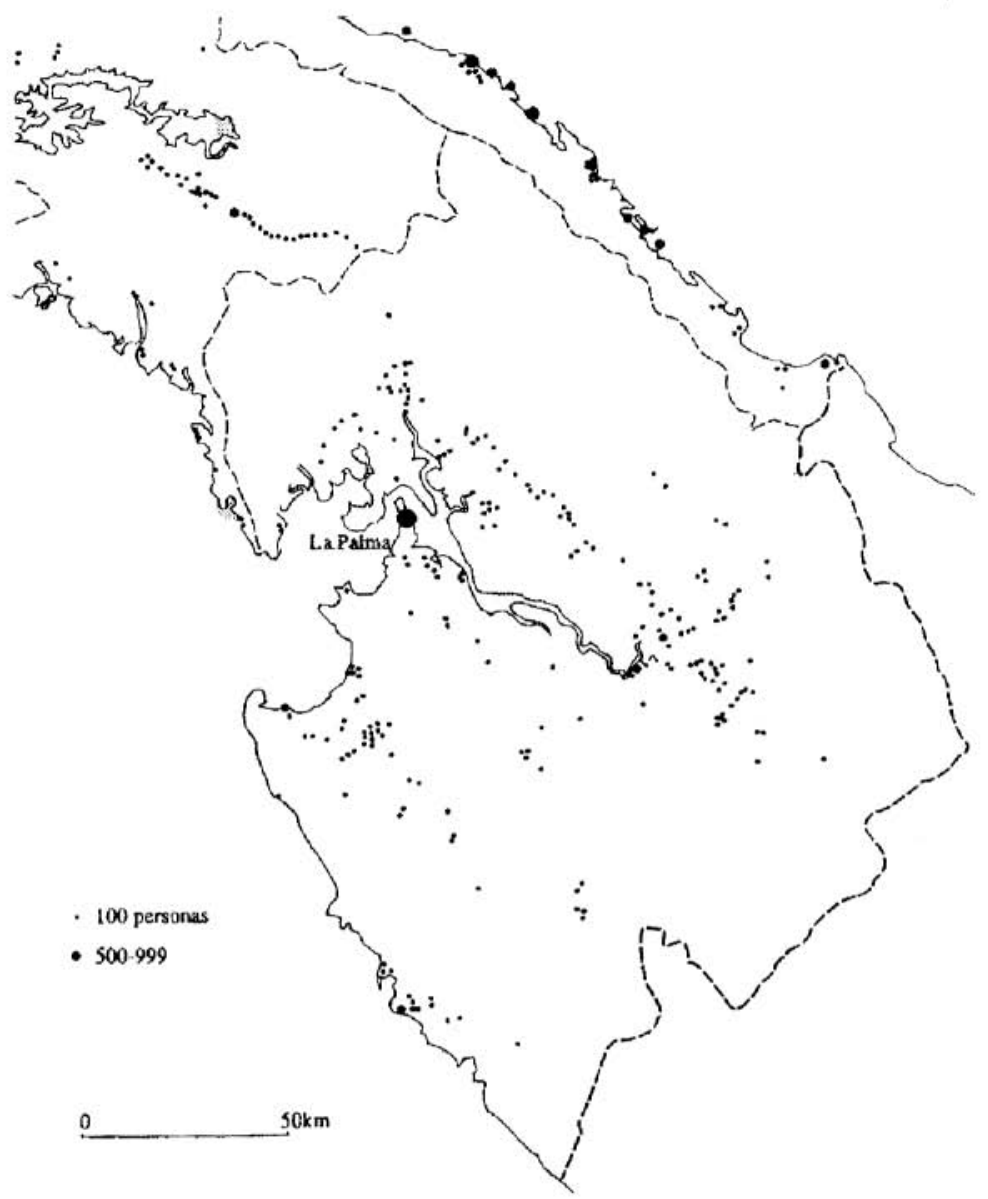

Figura 2. Distribución de la población. 
El incremento poblacional de estos poblados fue notorio durante las décadas de los setenta y ochenta, más no así en la de los noventa, en donde, a excepción de Yaviza, reflejan un alto porcentaje de disminución poblacional. Tal vez el caso más notorio es el de Yape, cuya disminución intercensal (1980-1990) fue de -62\%, situación que continúa debido a las incursiones de guerrilleros y paramilitares colombianos en el área.

Hoy, Yape es un pueblo con no más de 80 habitantes, entre adultos y niños. Sus residentes habituales están afincados allí desde hace más de 50 años. Otros, tienen unos 30 años de haber llegado desde poblaciones colombianas, han construido sus casas, trabajado sus tierras y criado a sus hijos en ese lugar, y se les ha provisto de un carnet de identificación que sustituya a la cédula panameña. Es un pequeño cacerío a orillas del río Tuira, cuyas casas están construidas con maderas, cañaza y pencas cimentadas sobre pilotes; no existe ningún tipo de infraestructura moderna. Sólo tienen una pequeña planta de energía para proveer electricidad a unas cuantas viviendas. No hay agua potable y mucho menos alcantarillados. Una casa hace las veces de tienda del lugar. Existe una pequeña iglesia y dos escuelas: una está en el mismo Yape, y otra en la zona donde viven los indígenas. Quienes viven en esta población, ya sea en calidad de desplazados (colombianos) o residentes criollos o indígenas, subsisten en medio del temor, la desesperanza y el pesimismo.

Y si bien los latinos e indígenas han mostrado su apoyo solidario a decenas de familias campesinas colombianas que han llegado a este lugar huyendo de la guerrilla y los paramilitares, los servicios de salud y de educación se ven afectados por la inseguridad que se da en el área.

Yape es sólo un ejemplo de lo que sucede desde hace algunos años en esta zona fronteriza que ha hecho suyo el conflicto armado colombiano y en donde la violación de los derechos humanos es un hecho común.

\section{LAS MIGRACIONES RECIENTES DE LOS CAMPESINOS COLOMBIANOS}

Los $240 \mathrm{~km}$ de la frontera colombo-panameña, selvática, y prácticamente desguarnecida, le abre a los campesinos de Urabá, Colombia, la posibilidad de caminar entre penurias, hacia un Darién que los recibe a costa del sacrificio de su paz y de su tranquilidad. Son gente pacífica a la que les ha caído el peso de una guerra, en la que los grandes intereses económicos entran en juego, y en las que las balas llueven sin piedad sobre las poblaciones.

La región de Urabá se encuentra en el cauce del río Atrato, entre los departamentos de Chocó, Antioquia y Córdoba, con una población de unos 
510000 habitantes, muchos de los cuales forman parte de las comunidades indígenas emberás - katios, kuna y zenus-. Es una de las regiones de mayor producción bananera en Colombia. (La comercialización del banano se da principalmente a través de la United Fruit Company desde hace décadas).

Urabá era una región de selva virgen, abrigo de los indígenas, pero, desde 1945, después del asesinato del caudillo liberal Jorge Eliecer Gaitán, la violencia azota los campos y los poblados colombianos y la gente se ve forzada a huir de la guerra, y entre las nuevas regiones que se están poblando, está Urabá.

A principios de 1960, la compañía bananera United Fruit Company se estableció lo cual atrajo más inmigrantes que buscaban empleos en las plantaciones. Se organizaron grandes sindicatos y las agrupaciones guerrilleras influyeron sobre estos gremios. Los terrratenientes y los grandes propietarios del área rechazaron como indeseables a los sindicatos.

La historia siguió larga y minuciosa. Las pugnas por el control de los sindicatos en la década de los ochenta, condujo a las Fuerzas Armadas Revolucionarias de Colombia (FARC) y al Ejército Popular de Liberación (EPL) a una confrontación entre ellos, con características semejantes a las que libraron contra el Estado y los terratenientes.

Esta situación le abrió las puertas a las fuerzas paramilitares, apoyados por el ejército colombiano, para que entraran a la región. La guerrilla perdió terreno. Los grupos paramilitares de las llamadas autodefensas campesinas de Colombia, impusieron su régimen de violencia y los moradores del área se vieron obligados a huir y muchos de ellos cruzaron la frontera y entraron a Darién.

Este contingente de refugiados, en su mayoría compuesto por campesinos pobres, ancianos, mujeres y niños, fue bien acogido entre los kunas y wounaan que demostraron sentimientos de solidaridad. Los emberás han sido más recelosos, pues consideran necesario preservar las tierras de su comarca y piensan que entrarán en peligro si albergan a los refugiados.

Al llegar al Darién, los refugiados buscan ubicarse en localidades cercanas al río Tuira. Allí construyen sus ranchos con hojas de tallo montañero, procuran algún jornal entre los vecinos y reciben donaciones de ropa y de alimentos de los moradores darienitas. Son temerosos de acudir a los centros de salud porque piensan que eso los delata como indocumentados y puedan ser deportados por las autoridades panameñas. Se caracterizan por ser gente trabajadora, amable y sencilla.

Además de los refugiados, a Darién han llegado guerrilleros y paramilitares colombianos que han extendido, hasta tierras panameñas, la guerra que tienen entre ellos, con todos los métodos de violencia que le caracterizan: 
secuestros, asesinatos selectivos, y nada exime que los militares comiencen con masacres masivas de campesinos.

Como toda situación de guerra, surgen elementos o grupos dedicados al pillaje y que actúan sin ninguna justificación política o militar, sino como delincuentes comunes. A ellos se suman la gente vinculada al narcotráfico. Estos elementos traen consigo dosis de violencia.

\section{LOS INDICADORES SOCIOECONÓMICOS DE LA REGIÓN}

Para obsevar el desarrollo socioeconómico del área, se eligió un conjunto de variables susceptibles de ser elaboradas con los datos estadísticos disponibles a nivel nacional, a fin de poder determinar el nivel de desarrollo de los distritos de la provincia del Darién y, en especial, de los distritos comarcales próximos a la frontera en relación con el resto del país.

Las variables elegidas fueron: grado de urbanización, nivel de educación, nivel de vida, y nivel de atención médico-sanitaria recibida por la población. Para cada variable se seleccionaron un conjunto de indicadores. Así, para el grado de urbanización se establecieron: a) Proporción de población urbana del distrito de acuerdo con la definición censal; b) Tasa de crecimiento demográfico por distrito; c) Población no dispersa, considerándose como tal, aquélla que habita en localidades de 500 habitantes o más; d) Población económicamente activa no agrícola; e) Servicio de comunicación existente.

La variable a nivel de educación se construyó con los siguientes indicadores: a) Sin ningún grado de educación aprobado; b) Población de 15 años y más con estudios primarios completos; c) Población de 15 años y más con algún grado de enseñanza secundaria; d) Población con algún grado de universidad.

La variable nivel de vida fue estudiada por los indicadores que siguen a continuación: a) Desnutrición infantil, según un censo levantado por los ministerios de Salud y Educación a nivel nacional, entre escolares de primer grado de educación primaria; b) Mortalidad infantil, según los cálculos del Ministerio de Planificación y Política Económica, y el Departamento de Planificación Social; c) Características de la vivienda a partir de la gran cantidad de variables señaladas por el censo de población y vivienda de 1990; d) Ingreso familiar mensual, de acuerdo con la información obtenida en el censo de 1990.

Para la variable atención médico-sanitaria, se emplearon los siguientes indicadores: a) Instituciones de atención médico-sanitarias; b) Personal técnico en los servicios estatales de salud; c) Atención médica en los casos de nacimientos y muertes. 
Los datos obtenidos permiten apreciar la forma como se distribuye en el país los distritos, según su nivel de desarrollo relativo, el cual fue ponderado como muy bajo para aquéllos que alcanzaron un índice promedio inferior a $20 \%$; bajo: entre $20.1 \%$ y $40 \%$; medio: entre $40.1 \%$ y $60 \%$; medio alto: entre $60.1 \%$ y $80 \%$, y alto más de $80 \%$.

La provincia del Darién tiene cuatro distritos de los cuales dos - Pinogana y Chepigana-, aglutinan $81.8 \%$ de la población de la provincia y presentan un nivel de desarrollo relativo bajo. Los otros dos, los distritos comarcales de Cémaco y Sambú (18.2\% de la población), aparecen como muy bajos, representando los índices de desarrollo relativo más bajos de toda la república, niveles que pueden considerarse como de extrema pobreza. Se trata de distritos muy faltos de vías de comunicación y con una población indígena con niveles muy bajos en todos los aspectos estudiados. A estos dos elementos habría que añadir, como característica de esta región, una gran dispersión en la distribución de la población e inexistencia de población urbana; alta proporción de población económicamente activa dedicada a la agricultura y bajísimos índices de niveles de vida, de educación y de atención médico-sanitaria. Se trata pues, de distritos absolutamente rurales.

\section{CONCLUSIONES}

Los procesos sociales que se desarrollan en la frontera colombo-panameña ponen en evidencia la falta de seguridad que se vive en esta zona, que debe ser escenario de ratificación de nuestra soberanía, y no refugio de poblaciones desplazadas, perseguidas o excluidas del sistema ecónomico y político vigente.

Es necesario afrontar con más fuerza e infraestructuras eficaces los graves problemas de pobreza, enfermedades, población desplazada, depredación ecológica, narcotráfico y contrabando que se dan en esta región.

Asimismo, esta frontera colombo-panameña de zona marginada, debe convertirse en un área de cooperación internacional; en escenario de colaboración interinstitucional en campos como la salud, el transporte, las comunicaciones, la educación, la protección ambiental, la lucha contra el narcotráfico y el respeto a la autodeterminación de los pueblos.

Por su misma biodiversidad y patrimonio cultural, esta frontera debe jugar un papel importante en los porcesos de integración socioecónomica de los pueblos de América.

La presencia del Parque Nacional Darién, reserva de la biosfera, es una atracción que puede explotarse a través de componentes que armonicen con el paisaje, sitios de alojamiento para investigadores, guardabosques, 
centros de salud y recreación que sirvan de infraestructura para comunidades indígenas y no indígenas asentadas en la zona.

En oposición a la frontera tico-panameña -que una vez superadas las disputadas y firmados los tratados limítrofes, se ha desarrollado como un área de integración y de cooperación regional-, la frontera colombopanameña ha actuado como un área de separación y de aislamiento para el desarrollo de la economía latinoamericana. 